\title{
O USO DE FONTES ORAIS NA PESQUISA EM HISTÓRIA DA EDUCAÇÃO
}

\author{
Resenha do livro: \\ GRAZZIOTIN, Luciane Sgarbi Santos; ALMEIDA, Dóris Bittencourt. Romagem do \\ tempo e recantos da memória. Reflexões metodológicas sobre História Oral. São \\ Leopoldo: Oikos, 2012.
}

\section{Resenha por:}

\section{José Edimar de Souza ${ }^{1}$}

A professora Luciane Sgarbi Santos Grazziotin é gaúcha, Doutora em Educação com ênfase em História da Educação pela Pontifícia Universidade Católica do Rio Grande do Sul. Fez doutorado sanduíche na Universidade Clássica de Lisboa sob a orientação do professor Doutor Rogério Fernandes. Atualmente é professora titular na graduação e no Programa de Pós-Graduação em Educação do Centro de Ciências Humanas da UNISINOS. A professora Dóris Bittencourt de Almeida é gaúcha, Doutora em Educação pelo Programa de Pós-graduação em Educação da Universidade Federal do Rio Grande do Sul. É professora adjunta de História da Educação da Faculdade de Educação, atuando junto ao Programa de Pós-Graduação em Educação da Universidade Federal do Rio Grande do Sul.

Romagem do tempo e recanto da memória é uma obra que reúne o interesse de duas pesquisadoras cuja afinidade intelectual e as aproximações dos temas investigados nos seus doutoramentos possibilitaram encontrar pontos de contatos. O viés condutor da obra é a opção pela escolha das fontes orais como campo metodológico, aspecto que agrega relevância a esta obra.

"Romagem", por definição é uma peregrinação, uma espécie de percurso que se trilha, por um determinado período. É nesse sentido que a expressão adquire consistência, pois, a obra apresenta os caminhos construídos por estas pesquisadoras, em tempos distintos, mas com o mesmo propósito!

Luciane Grazziotin realiza analise das memórias a partir do Acervo Municipal de Memória Oral de Bom Jesus. Na sua pesquisa de doutorado inventaria e analisa a história da educação desta cidade, localizada no interior do Rio Grande do Sul, entre os anos de 1913, data de emancipação do município e 1963, comemoração do seu cinqüentenário. Utilizando a História Oral como metodologia, analisaram-se os discursos e conteúdos referentes ao ato memorialístico, as lembranças e os esquecimentos de um passado e a possibilidade de construção de uma história da educação desse lugar, nesse tempo a partir dos lugares de memória criados pelo Projeto.

Dóris Almeida desenvolve sua investigação acerca da história da educação do Rio Grande do Sul; particularmente no âmbito da história da educação rural e da formação docente, durante as décadas de 1950 e 1960. Entrevista alunos, professores e funcionários que vivenciaram uma experiência educativa inédita na Escola Normal Rural Pública de Osório - Rio Grande do Sul. A pesquisa concluiu que o processo de memória não é algo puramente individual e que não representa exatamente o que se passou. Nesse sentido, é fruto de uma construção social desenvolvida por um grupo de sujeitos que constituem uma comunidade de memória, é que de certo modo, marcam as construções de suas identidades. 
O prefácio apresenta a relação constituída pelas pesquisadoras e é assinado pelas professoras pesquisadoras: doutora Maria Helena Câmara Bastos e doutora Maria Stephanou que orientaram os estudos das autoras, na ocasião da realização da pesquisa de doutorado. Para Bastos e Stephanou (2012, p. 8) "[...] aprender a pesquisar decorre de um processo lento e repleto de hesitações.". Nesse sentido, Luciane e Dóris buscam, de forma generosa, socializar suas escolhas metodológicas, bem como, enfatizam o modo como seus objetos de estudo foram construídos.

O livro está estruturado em seis partes, além da introdução. Na introdução, as autoras reafirmam o desejo da concretização deste projeto, ou seja, a possibilidade de alcançar para a comunidade acadêmica este trabalho que partilha um pouco dos resultados obtidos nos seus estudos de doutoramento. Nesse sentido, as autoras definem a obra como uma "espécie de ferramenta" para todos aqueles que desejarem conhecer um pouco mais sobre as pesquisas cujo referencial teórico esteja ancorado na História Cultural e o suporte metodológico na História Oral.

Na primeira parte, intitulada "Deslocamentos para iniciar a reflexão", Grazziotin e Almeida justificam e fundamentam quanto à perspectiva de utilização das fontes orais em contexto que ultrapassa paradigmas instituídos na Modernidade. O que exigiu compreender que o trabalho com memória, transcrevendo e organizando as narrativas e tratando-as considerando-a como documento é uma tarefa complexa, em função da sua relatividade e subjetividade. Desse modo, cada uma das pesquisadoras assumiu uma possibilidade no percurso de separar, de produzir e de transformar em documentos as memórias dos diferentes sujeitos que foram entrevistados.

"Tempo de memória" refere-se à segunda parte da obra. Nela, Luciane e Dóris argumentam sobre os tempos e o sentido atribuído à memória. As autoras sustentam-se teoricamente em autores como Halbwachs (2006), Ricouer (1994) e Chartier (2002), entre outros. Portanto, o tempo é entendido a partir da forma assumida por cada sujeito para expressar as suas práticas e a memória social, considerando a convivência social e em grupo como definidora de uma representação coletiva sobre o tempo.

As referidas autoras abordam a memória coletiva no plural, considerando que estas são constituídas por lembranças do passado que transcendem a individualidade e é compartilhada socialmente no domínio da vida comum. As memórias encontram-se ancoradas na história individual e emergem à medida que são feitos os encadeamentos e as relações do que é manifestado nas lembranças. A memória torna-se, portanto, o caminho pelo qual a existência retorna esculpindo a história.

$\mathrm{Na}$ terceira parte, "História oral: escolhas e trajetórias das pesquisas", a caracterização do espaço, dos sujeitos, da realização das entrevistas, do uso do diário de pesquisa e análise é explicitada. Além de discorrer sobre a realização da entrevista; cuidados com os registros; uso do gravador, este capítulo também se dedica ao detalhamento do uso de acervos de memória oral.

A opção metodológica da História Oral se deve à possibilidade de que a oralidade representa para se elucidar trajetórias individuais, coletivas, eventos ou processos, conferindo status a uma nova abordagem histórica. Grazziotin e Almeida apoiadas em Amado e Ferreira (2002) argumentam que na História Oral, o documento principal é a narrativa que, a partir de técnicas e pressupostos, é organizado pelo pesquisador; portanto, o rigor ético do historiador, no tratamento, organização e construção das narrativas, configura novas formas interpretativas para o trabalho histórico.

"A História da educação em Bom Jesus" é o título da quarta parte e "Escola Normal Rural de Osório", o título da quinta parte. Na quarta parte Luciane desenvolve uma síntese dos resultados de sua investigação de doutorado, e enfatiza aspectos da 
metodologia que contribuíram para compor e contar uma história da educação de Bom Jesus, município situado na região noroeste do Rio Grande do Sul. Na quinta parte Dóris constrói também uma síntese de seu estudo de doutorado, destacando categorias analisadas em torno das memórias sobre a Escola Normal Rural, como a formação de lideranças, as identidades de pertencimento e as "vozes dissonantes".

A sexta parte é destinada às considerações finais. Grazziotin e Almeida argumentam que a escrita deste livro representou a continuidade às discussões iniciadas nas investigações de doutorado. Concluem que no decorrer da obra buscaram construir uma abordagem que envolvesse o leitor na compreensão de alguns labirintos epistemológicos, ampliando critérios de usos das fontes orais nos processos investigativos no campo da História da Educação. O modo como as narrativas foram apresentadas, selecionadas e organizadas neste livro esclarece sobre a amplitude da compreensão sobre o tema investigado, afinal, como elas sintetizam: "não saímos de um processo de escrita do mesmo jeito que entramos". (GRAZZIOTIN; ALMEIDA, 2012, p. 104). A construção textual produziu uma espécie de teia de relações a partir da iniciativa de entrelaçar as duas pesquisas, e identifica-se o diálogo realizado pelas autoras, fruto de suas reflexões e desdobramentos sobre as pesquisas com memória e História Oral.

As memórias reunidas, organizadas e analisadas, reconstruíram um tempo escolar que expressa a utilização histórica associada a uma dinâmica prática, que evidencia elementos da cultura escolar, do ritual escolar, de objetos que povoaram o cotidiano, as práticas educativas e até mesmo uma arquitetura escolar.

Quando se utiliza a memória como objeto de pesquisa é preciso reconhecer suas fragilidades, pois se pode lembrar e esquecer, ou até mesmo reinventar certos aspectos de nosso passado pessoal e/ou coletivo. Este aspecto é o que se conhece como "memória vicária", caracterizada pela prática de tornar as memórias dos outros como parte da realidade para aqueles que ouvem as memórias, mas não possuíam a experiência da mesma. Estas memórias, ao serem compartilhadas, se transformam em memórias de um grupo social e que passam a ser assimiladas como uma memória coletiva aspecto que se percebe ao longo da obra escrita por Luciane Grazziotin e Dóris Almeida.

\section{Referências}

AMADO, Janaína; FERREIRA, Marietade Moraes (Org.). Usos \& abusos da história oral. 5. ed. Rio de Janeiro: FGV, 2002.

BASTOS, Maria Helena Câmara. STEPHANOU, Maria. Um convite à leitura. Memórias \& itinerários de pesquisa. In: GRAZZIOTIN, Luciane Sgarbi Santos; ALMEIDA, Dóris Bittencourt. Romagem do tempo e recantos da memória. Reflexões metodológicas sobre História Oral. São Leopoldo: Oikos, 2012, p. 7-9.

CHARTIER, Roger. À beira da falésia: a história entre incertezas e inquietudes. Trad. RAMOS, Patrícia Chittoni, Porto Alegre: Ed. Universidade/UFRGS, 2002.

HALBWACHS, Maurice. A memória coletiva. São Paulo: Ed. Centauro, 2006.

RICOUER, Paul. Tempo e narrativa (tomo 1). Campinas: Papirus, 1994.

\footnotetext{
${ }^{1}$ Graduado em História, Mestre e Doutor em Educação pela UNISINOS com bolsa CAPES/PROEX. Pósdoutorando em Educação UNISINOS. Professor e Especialista em Educação na Fundação Escola Técnica Liberato Salzano Vieira da Cunha e Vice-diretor da EMEF Senador Salgado Filho de Novo Hamburgo. Integra o grupo de pesquisa EBRAMIC - Educação no Brasil: memória, instituições e cultura escolar. Email: profedimar@gmail.com.
} 